\title{
"FACTORES RELACIONADOS A LA AUTOMEDICACIÓN EN LA POBLACIÓN ESTUDIANTIL DE ENFERMERÍA Y OBSTETRICIA EN LA UNIVERSIDAD PRIVADA DE HUANCAYO EN EL PERÍODO 2012".
}

\section{RESUMEN}

La automedicación puede ser definida de forma genérica como la administración por decisión propia, o por consejo no cualificado, de medicamentos para aliviar un síntoma o curar una enfermedad. La automedicación representa un problema más complejo ya que entran aspectos atribuibles a la población como la educación médica, la cultura, los usos y costumbres, que de alguna manera son influenciados por el gran aparato de la comercialización con que cuentan las empresas productoras de medicamentos.

La investigación consideró determinar los factores relacionados a la automedicación en la población estudiantil de enfermería y obstetricia en la Universidad Privada de Huancayo.

El diseño que se empleó responde a la de una investigación por objetivos tomando como referencia la naturaleza de la variable (causa - efecto), empleados en la formulación del problema planteado.

De acuerdo a los resultados obtenidos se afirma que existe automedicación en la población estudiantil, siendo para la carrera de enfermería en un $96.83 \%$ y para obstetricia en un $94.12 \%$. Los medicamentos que más se auto medican son los : antibióticos, analgésicos y antiinflamatorios en porcentajes de $69.04 \%$ en los alumnos que estudian enfermería y $66.18 \%$ en obstetricia , los procesos patológicos por los que se auto medican son Resfriado común y dolores corporales $47.62 \%$ en los alumnos de enfermería y $51.47 \%$ en obstetricia.

Los medios de comunicación que influyeron en los alumnos de la Carrera Profesional de Enfermería para auto medicarse fueron: Televisión 64.28 \% y para los alumnos de obstetricia en un $60.29 \%$.

Palabras Claves: Automedicación, medicamentos, enfermedades.

\section{SUMMARY:}

Self-medication can be defined generically as the administration by choice, or by unqualified advice, medicines to relieve symptoms or cure a disease. Self-medication is a problem more complex since entering the population attributable aspects such as medical education, culture, habits and customs that are somehow influenced by the big marketing machine that have drug manufacturing companies.

The investigation considered to determine the factors related to self-medication in the student population of nursing and midwifery at the Private University of Huancayo. 
The design that was used corresponds to the objectives of an investigation by reference to the nature of the variable (cause - effect) used in the formulation of the problem. According to the results of self-medication is said to exist in the student population, still nursing career for a $96.83 \%$ and $94.12 \%$ in obstetrics. The drugs most are selfmedicate antibiotics, analgesics and antiinflammatory in percentages of $69.04 \%$ in students studying nursing and $66.18 \%$ in obstetrics, pathological processes by which self-medicate are common cold and body aches $47.62 \%$ in nursing students and $51.47 \%$ in obstetrics. The media that influenced the students of the Nursing Careers for self-medication were: TV $64.28 \%$ and for students of obstetrics by $60.29 \%$.

Keywords: Self-medication, medications, diseases.

\section{INTRODUCCIÓN}

La automedicación está definida como el uso de medicamentos por decisión propia o por consejo de terceras personas que no tienen conocimientos a cerca de los medicamentos y las enfermedades; es decir, cualquier persona ajena (amigos, vecinos, algún familiar etc.). Es una práctica muy antigua que constituye una problemática de carácter tanto a nivel nacional como mundial; debido a que es imposible que ella desaparezca de nuestra sociedad, por ello es preciso que se logre una automedicación responsable, representa un severo problema de salud pública, ya que puede ocasionar graves daños a la salud individual, familiar y colectiva ${ }^{[1]}$.

La automedicación se ha convertido en una actividad frecuente de las personas y esta acción riesgosa constituye una prioridad de carácter social. Es primordial la prevención de las enfermedades, así como también la superación de la salud de cada individuo. Es indispensable, también, controlar y asegurar el uso racional de los medicamentos. El propósito de la presente investigación es Determinar los factores relacionados a la automedicación en la población estudiantil de enfermería y obstetricia en la Universidad Privada de Huancayo "Franklin Roosevelt".

\section{OBJETIVOS DE LAINVESTIGACIÓN}

\section{Objetivo general}

Determinar los factores relacionados a la automedicación en la población estudiantil de enfermería y obstetricia en la Universidad Privada de Huancayo.

\section{Objetivos específicos}

1. Determinar el porcentaje de automedicación de la población estudiantil de enfermería y obstetricia de la Universidad Privada de Huancayo

2. Determinar la prevalencia de automedicación según género.

3. Determinar la prevalencia de automedicación según edad.

4. Determinar la prevalencia de automedicación según condición socioeconómica.

5. Determinar la prevalencia de automedicación según procesos patológicos.

6. Determinar la prevalencia de automedicación según medios de comunicación.

7. Determinar la prevalencia de automedicación según tipo de medicamentos consumidos por los estudiantes.

\section{METODOLOGÍA}

El diseño que se empleo responde a la de una investigación por objetivos tomando como referencia la naturaleza de la variable (causa - efecto), empleados en la formulación del problema planteado.

\section{Método de la investigación: Encuesta}

Población de estudio: La población de la investigación están constituida por 375 alumnos donde 132 son de de la carrera profesional de obstetricia y 243 de la carrera enfermería de Universidad Privada de Huancayo.

Muestra: Para determinar el tamaño muestral se utilizará la fórmula para poblaciones finitas con un nivel de confiabilidad de un $95 \%$ con un margen de error de $5 \%$.Teniendo como muestra 194 a quienes se le aplicó la encuesta 
Luego para aplicar el tamaño de cada estrato se aplico la fórmula del reparto proporcional simple del autor Sierra Bravo que es el siguiente:

\begin{tabular}{|l|c|c|c|}
\hline \multicolumn{1}{|c|}{$\begin{array}{c}\text { Carreras } \\
\text { profesionales }\end{array}$} & $\begin{array}{c}\text { Sub } \\
\text { población }\end{array}$ & Estratos & $\begin{array}{c}\text { Su amplitud en } \\
\text { muestra }\end{array}$ \\
\hline Obstetricia & 132 & $35.20 \%$ & 68 \\
\hline Enfermería & 243 & $64.80 \%$ & 126 \\
\hline Total & 375 & $100 \%$ & 194 \\
\hline
\end{tabular}

Fuente: Oficina de Registro Central de Grados y Títulos de la UPH.

\section{RESULTADOS}

1. ¿Usted se automedica o consume medicamentos por decisión propia o recomendada por terceros?

\begin{tabular}{|c|c|c|c|c|c|}
\hline SEXO & SI & $\begin{array}{c}\text { PORCENTAJE } \\
(\%)\end{array}$ & NO & $\begin{array}{c}\text { PORCENTAJE } \\
(\%)\end{array}$ & TOTAL \\
\hline MASCULINO & 16 & 16.69 & 00 & 00 & 16 \\
\hline FEMENINO & 106 & 82.12 & 04 & 3.17 & 110 \\
\hline
\end{tabular}

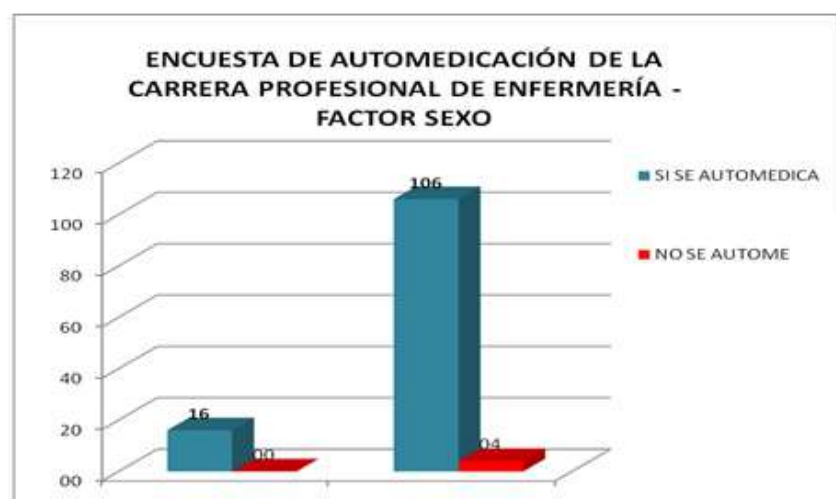

medicamentos por decisión propi: recomendada por terceros?

\begin{tabular}{|c|c|c|c|c|}
\hline EDAD & SI & $\begin{array}{c}\text { PORCENTAJE } \\
(\%)\end{array}$ & NO & $\begin{array}{c}\text { PORCENTAJE } \\
(\%)\end{array}$ \\
\hline MENORES DE 18 ANOS & 16 & 12.7 & 00 & 0 \\
\hline $\begin{array}{c}\text { DE 18 ANOS A 20 } \\
\text { ANNOS }\end{array}$ & 51 & 40.47 & 03 & 2.39 \\
\hline MAYORES DE 20 AÑOS & 55 & 43.65 & 01 & 0.79 \\
\hline
\end{tabular}

\section{ENCUESTA DE AUTOMEDICACIÓN DE LA}

CARRERA PROFESIONAL DE ENFERMERÍA -

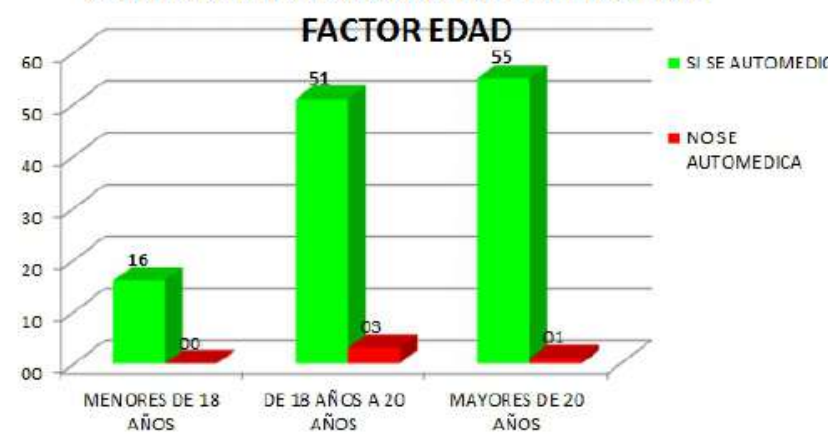

\begin{tabular}{|c|c|c|}
\hline NIVEL SOCIO - ECONOMICO & $\begin{array}{c}\text { ALUMNOS } \\
\text { ENCUESTADOS }\end{array}$ & PORCENTAJE (\%) \\
\hline BAJO & 16 & 12.70 \\
\hline MEDIO & 109 & 86.50 \\
\hline ALTO & 01 & 0.80 \\
\hline TOTAL & $\mathbf{1 2 6}$ & $\mathbf{1 0 0}$ \\
\hline
\end{tabular}

NIVEL SOCIO - ECONÓMICO DE LOS ALUMNOS DE LA CARRERA PROFESIONAL DE ENFERMERÍA

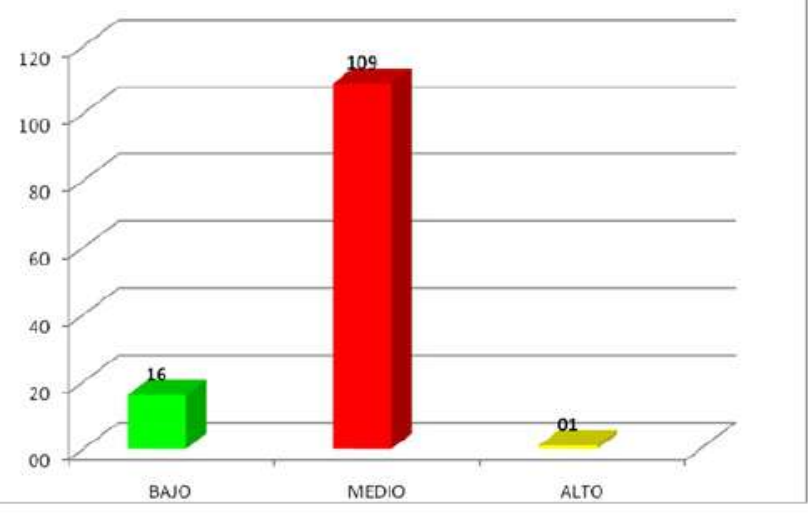

Fuente: Elaborado por los autores - 2012

3. ¿Para qué enfermedades, consume usted los medicamentos por iniciativa propia o inducida por terceros?

\begin{tabular}{|l|c|c|}
\hline \multicolumn{1}{|c|}{ ENFERMEDADES } & RESPUESTAS & $\begin{array}{c}\text { PORCENTAJE } \\
(\%)\end{array}$ \\
\hline $\begin{array}{l}\text { RESFRIADO COMUN Y DOLORES } \\
\text { CORPORALES }\end{array}$ & 45 & 35.71 \\
\hline $\begin{array}{l}\text { CEFALEAS, TRASTORNOS RESPIRATORIOS } \\
\text { (tos, bronquitis, amigdalitis) Y TRASTORNOS } \\
\text { GASTROINTESTINALES (dolor de estómago, } \\
\text { diarrea, nauseas) }\end{array}$ & 60 & 47.62 \\
\hline PROBLEMAS ALERGICOS & 13 & 10.32 \\
\hline NINGUNO TOTAL & 08 & 6.35 \\
\hline \multicolumn{1}{|c|}{} & $\mathbf{1 2 6}$ & 100 \\
\hline
\end{tabular}

AUTOMEDICACIÓN EN ALUMNOS DE LA CARRERA PROFESIONAL DE ENFERMERIA RELACIONADOS CON ALGUNAS ENFERMEDADES

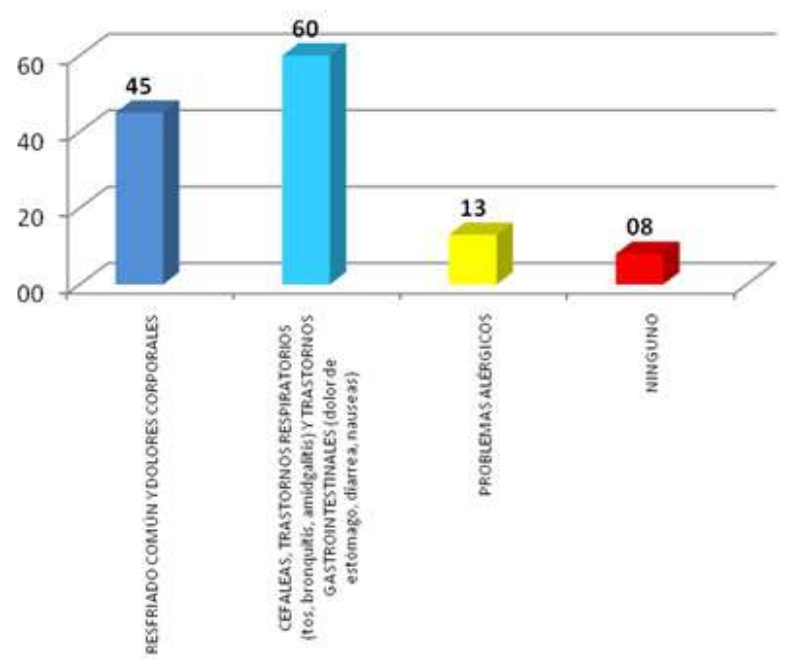

4. ¿Qué medios de comunicación influyeron en usted para auto medicarse o consumir medicamentos por iniciativa propia?

\begin{tabular}{|c|c|c|}
\hline MEDIOS DE COMUNICACION & RESPUESTAS & PORCENTAJE (\%) \\
\hline TV & 81 & 64.29 \\
\hline RADIO & 11 & 8.73 \\
\hline VIRTUAL & 18 & 14.28 \\
\hline PROPAGANDAS IMPRESAS & 13 & 10.32 \\
\hline NINGUNO & 03 & 2.38 \\
\hline TOTAL & $\mathbf{1 2 6}$ & $\mathbf{1 0 0}$ \\
\hline
\end{tabular}




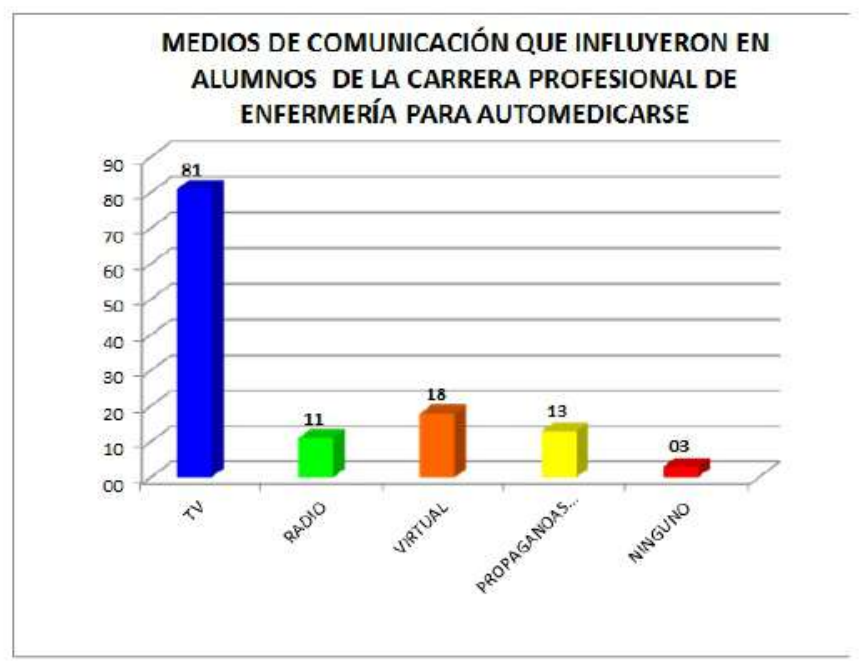

Fuente: Elaborado por los autores - 2012

5. ¿Qué tipos de medicamentos consume mayormente sin prescripción médica?

\begin{tabular}{|c|c|c|}
\hline MEDIOS DE COMUNICACION & RESPUESTAS & PORCENTAJE (\%) \\
\hline $\begin{array}{c}\text { ANTIBIOTICOS, ANALGÉSICOS } \\
\text { ANTIINFLAMATORIOS }\end{array}$ & 87 & 69.04 \\
\hline ANTITUSIVO & 08 & 6.35 \\
\hline VITAMINAS & 27 & 21.43 \\
\hline ANSIOLiTICOS & 02 & 1.59 \\
\hline NINGUNO & 02 & 1.59 \\
\hline TOTAL & $\mathbf{1 2 6}$ & $\mathbf{1 0 0}$ \\
\hline
\end{tabular}

MEDICAMENTOS CONSUMIDOS POR LOS ALUMNOS DE LA CARRERA PROFESIONAL DE ENFERMERÍA SIN PRESCRIPCIÓN MÉDICA

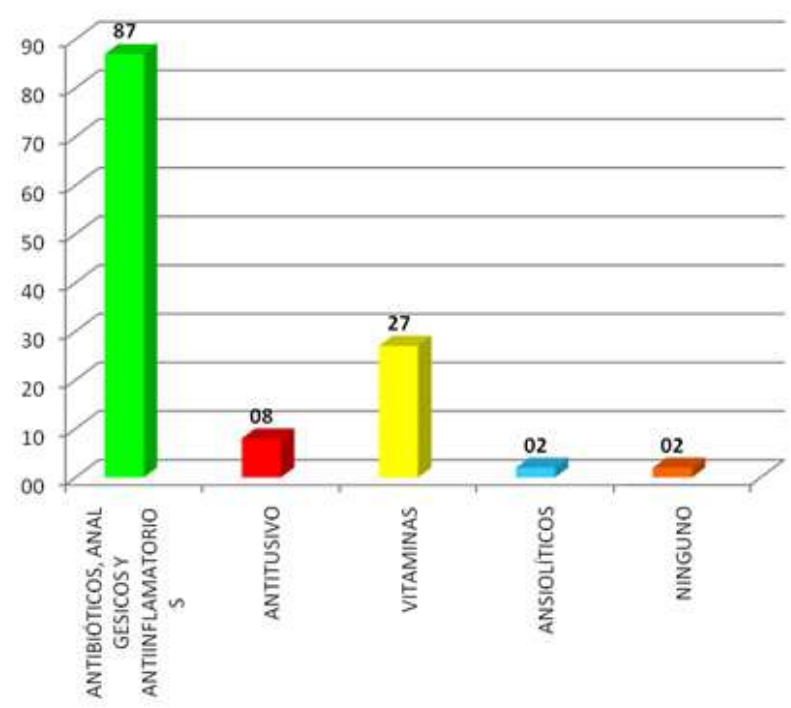

1. ¿Usted se automedica o consume medicamentos por decisión propia o recomendada por terceros?

\begin{tabular}{|c|c|c|c|c|c|}
\hline SEXO & SI & $\begin{array}{c}\text { PORCENTAJE } \\
(\%)\end{array}$ & NO & $\begin{array}{c}\text { PORCENTAJE } \\
(\%)\end{array}$ & TOTAL \\
\hline MASCULINO & 06 & 8.82 & 00 & 00 & 06 \\
\hline FEMENINO & 58 & 85.29 & 04 & 5.88 & 62 \\
\hline \multicolumn{7}{|c|}{ TOTAL } & 68 \\
\hline
\end{tabular}

ENCUESTA DE AUTOMEDICACIÓN DE LA CARRERA PROFESIONAL DE OBSTETRICIA FACTOR SEXO

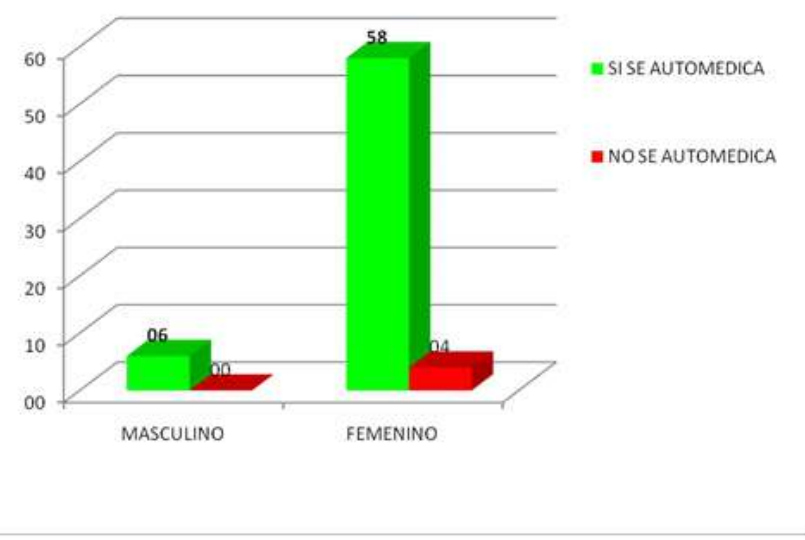

Fuente: Elaborado por los autores - 2012

1. ¿Usted se automedica o consume medicamentos por decisión propia o recomendada por terceros?

\begin{tabular}{|c|c|c|c|c|c|}
\hline EDAD & SI & $\%$ & NO & $\%$ & TOTAL \\
\hline MENORES DE 18 AÑOS & 12 & 17.65 & 00 & 00 & 12 \\
\hline DE 18 A 20 ANOS & 44 & 64.71 & 02 & 2.94 & 46 \\
\hline MAYORES DE 20 ANNOS & 08 & 11.76 & 02 & 2.94 & 10 \\
\hline
\end{tabular}

ENCUESTA DE AUTOMEDICACIÓN DE LA CARRERA PROFESIONAL DE OBSTETRICIA - FACTOR EDAD

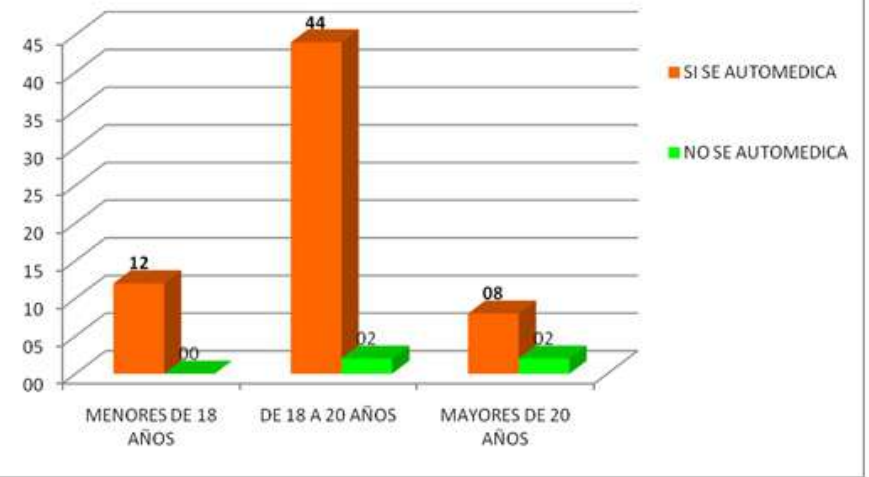

2. ¿En qué nivel socio - económico se ubica usted?

\begin{tabular}{|c|c|c|}
\hline $\begin{array}{c}\text { NIVEL SOCIO } \\
\text { ECONOMICO }\end{array}$ & $\begin{array}{c}\text { ALUMNOS } \\
\text { ENCUESTADOS }\end{array}$ & PORCENTAJE (\%) \\
\hline BAJO & 05 & 7.35 \\
\hline MEDIO & 63 & 92.65 \\
\hline ALTO & 00 & 00 \\
\hline TOTAL & 68 & 100 \\
\hline & & \\
\hline
\end{tabular}




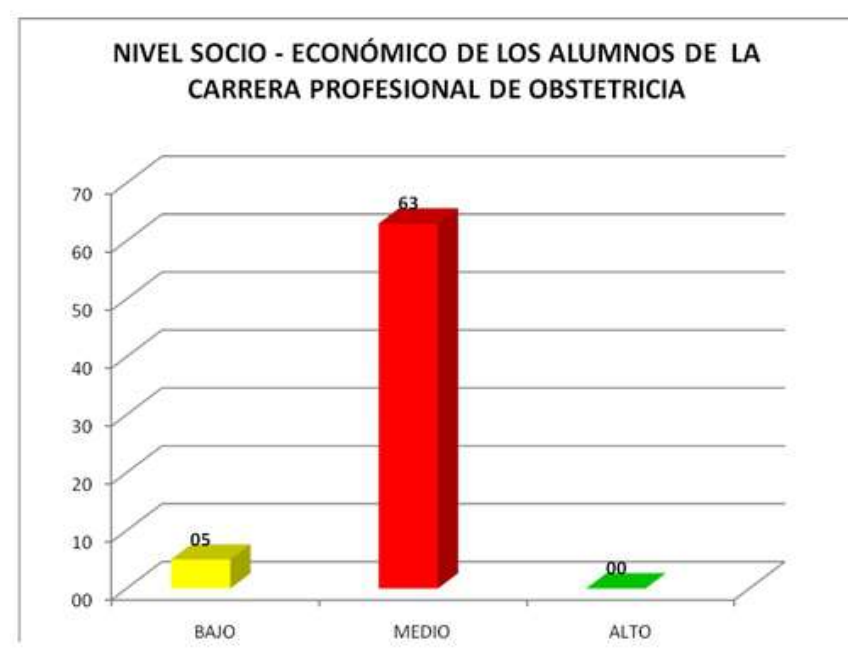

3. ¿Para qué enfermedades, consume usted los medicamentos por iniciativa propia o inducida por terceros?

\begin{tabular}{|c|c|c|}
\hline ENFERMEDADES & RESPUESTAS & $\begin{array}{c}\text { PORCENTAJE } \\
(\%)\end{array}$ \\
\hline $\begin{array}{c}\text { RESFRIADO COMUNYYDOLORES } \\
\text { CORPORALES }\end{array}$ & 35 & 51.47 \\
\hline $\begin{array}{c}\text { CEFALEAS, TRASTORNOS } \\
\text { RESPIRATORIOS (tos, bronquitis, } \\
\text { amigdalitis) Y TRASTORNOS } \\
\text { GASTROINTESTINALES (dolor de } \\
\text { estómago, diarrea, nauseas) }\end{array}$ & 23 & 33.83 \\
\hline PROBLEMAS ALERGICOS & 05 & 7.35 \\
\hline NINGUNO & 05 & 7.35 \\
\hline TOTAL & $\mathbf{6 8}$ & $\mathbf{1 0 0}$ \\
\hline & & \\
\hline
\end{tabular}

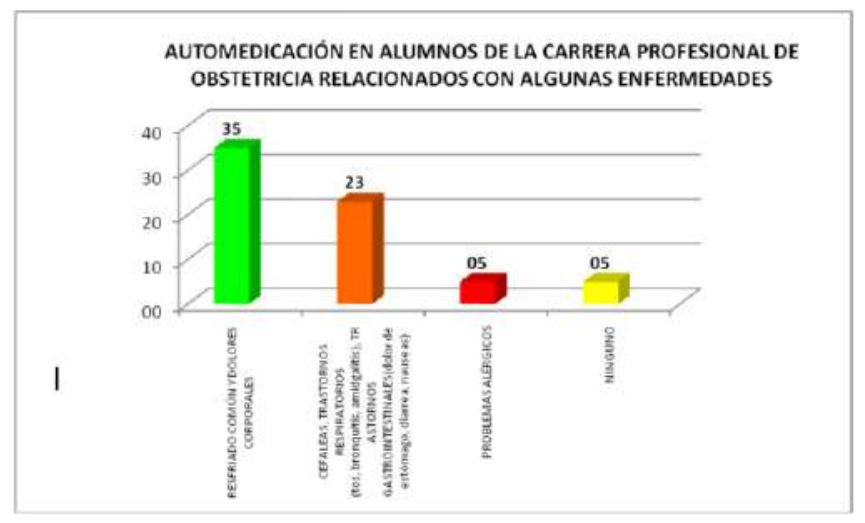

Fuente: Elaborado por los autores - 2012

4. ¿Qué medios de comunicación influyeron en usted para automedicarse o consumir medicamentos por iniciativa propia?

\begin{tabular}{|c|c|c|}
\hline MEDIOS DE COMUNICACION & RESPUESTAS & $\begin{array}{c}\text { PORCENTAJE } \\
(\%)\end{array}$ \\
\hline TV & 41 & 60.29 \\
\hline RADIO & 08 & 11.77 \\
\hline VIRTUAL & 08 & 11.77 \\
\hline PROPAGANDAS IMPRESAS & 05 & 7.35 \\
\hline NINGUNO & 06 & 8.82 \\
\hline TOTAL & 68 & 100 \\
\hline
\end{tabular}

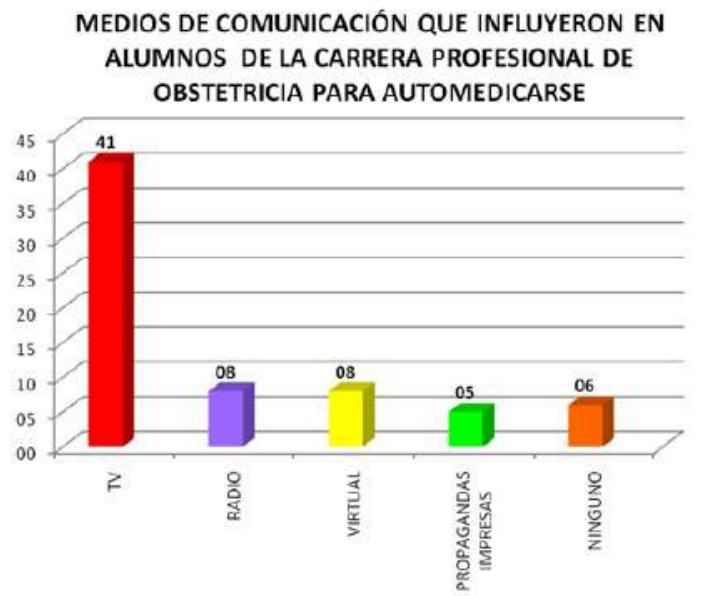

5. ¿Qué tipos de medicamentos consume mayormente sin prescripción médica?

\begin{tabular}{|c|c|c|}
\hline MEDIOS DE COMUNICACION & RESPUESTAS & PORCENTAJE (\%) \\
\hline $\begin{array}{c}\text { ANTIBIOTICOS, ANALGESICOS } \\
\text { ANTIINFLAMATORIOS }\end{array}$ & 45 & 66.18 \\
\hline ANTITUSIVO & 01 & 1.47 \\
\hline VITAMINAS & 19 & 27.94 \\
\hline ANSIOLITICOS & 01 & 1.47 \\
\hline NINGUNO & 02 & 2.94 \\
\hline TOTAL & $\mathbf{6 8}$ & $\mathbf{1 0 0}$ \\
\hline \multicolumn{2}{|r}{}
\end{tabular}

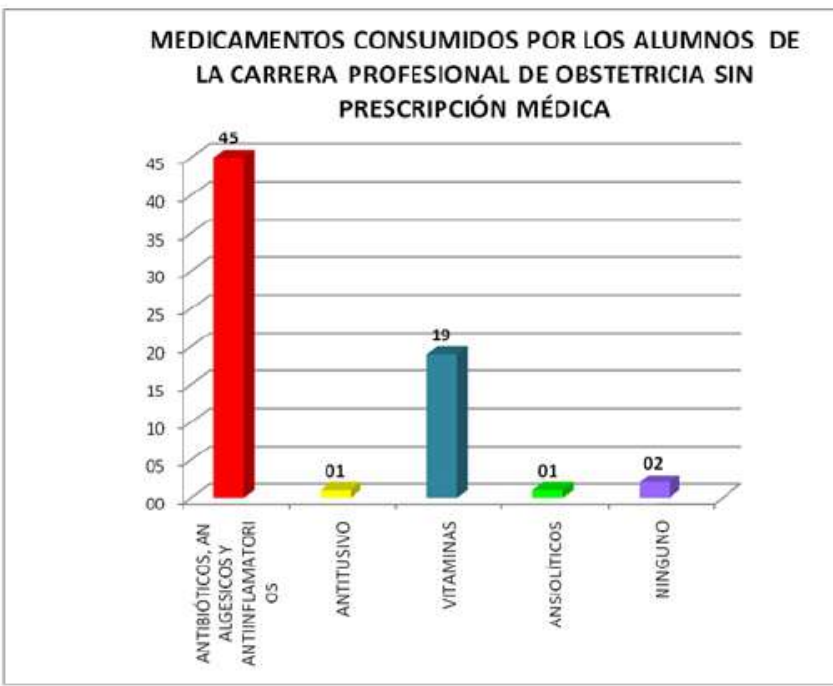

Fuente: Elaborado por los autores - 2012

\section{CONCLUSIONES:}

1. De los 126 alumnos de la Carrera Profesional de Enfermería se automedican $96.83 \%$ (122), no se auto medican 3.11\% (04). De los 68 alumnos de la Carrera Profesional de Obstetricia se automedican $94.12 \%$ (64) y no se automedican $5.88 \%$ (04).

2. De los 126 alumnos de ambos sexos, encuestados en la Carrera Profesional de Enfermería se automedican el $16.69 \%$ (16) del sexo masculino, $82.12 \%$ (106) del sexo femenino y no se automedican el $3.17 \%$ (04) del sexo femenino. 
De los 68 alumnos de ambos sexos, encuestados en la Carrera Profesional de Obstetricia se automedican el $8.82 \%$ (6) del sexo masculino, $85.29 \%$ (58) del sexo femenino y no se automedican $5.88 \%(04)$ del sexo femenino.

3. Alumnos de la Carrera Profesional de Enfermería menores de 18 años que se automedican $12.70 \%$ (16), de 18 a 20 años $40.47 \%$ (51), mayores de 20 años $43.65 \%$ (55) y no se automedican de 18 a 20 años $2.39 \%$ (03), mayores de 20 años $0.79 \%$ (01). Alumnos de la Carrera de Profesional Obstetricia menores de 18 años que se automedican $17.64 \%$ (12), de 18 a 20 años $64.70 \%$ (44), mayores de 20 años $11.76 \%$ (08) y no se automedican de 18 a 20 años $2.94 \%$ (02), mayores de 20 años $2.94 \%$ (02).

4. De acuerdo al nivel socio económico de los alumnos de la Carrera Profesional de Enfermería que se automedican pertenecen al nivel bajo $12.70 \%$ (16), medio $86.50 \%$ (109), alto $0.80 \%$ (01) y de los alumnos de la Carrera Profesional de Obstetricia que se automedican pertenecen al nivel socio - económico bajo $7.35 \%$ (05), medio $92.65 \%$ (63).

5. De acuerdo a los procesos patológicos por los que se automedican los alumnos de las Carrera Profesional de Enfermería se tiene: Resfriado común y dolores corporales $47.62 \%$ (60); trastornos respiratorios (tos, bronquitis, amigdalitis) y trastornos digestivos (dolor de estómago, diarrea, nauseas) $35.7 \%$ (45); problemas alérgicos $10.32 \%$ (13) y ninguno $6.35 \%$ (08).
De acuerdo a los procesos patológicos por los que se automedican los alumnos de las Carrera Profesional de Obstetricia se tiene: Resfriado común y dolores corporales $51.47 \%$ (35); trastornos respiratorios (tos, bronquitis, amigdalitis) y trastornos digestivos (dolor de estómago, diarrea, nauseas) $33.83 \%$ (23); problemas alérgicos $7.35 \%$ (05) y ninguno $7.35 \%(05)$.

6. Los medios de comunicación que influyeron en los alumnos de la Carrera Profesional de Enfermería para automedicarse fueron: Televisión $64.28 \%$ (81), radio $8.73 \%$ (11), virtual $14.28 \%$ (18), propagandas impresas $10,32 \%$ (13) y ninguno $2.38 \%$ (03).

Los medios de comunicación que influyeron en los alumnos de Obstetricia para automedicarse fueron: Televisión $60.29 \%$ (41), radio $11.76 \%$ (08), virtual $11.76 \%$ (08), propagandas impresas $7.35 \%$ (05), y ninguno $8.82 \%(06)$.

7. Los medicamentos consumidos $\sin$ prescripción médica por los alumnos de la Carrera Profesional de Enfermería son: antibióticos, analgésicos y antiinflamatorios $69.04 \%$ (87), antitusivos $6.35 \%(08)$, vitaminas $21.43 \%$ (27), ansiolíticos $1.59 \%$ (02) y ninguno $1.59 \%$ (02).Los medicamentos consumidos sin prescripción médica por los alumnos de la Carrera Profesional de Obstetricia son: antibióticos, analgésicos y antiinflamatorios $66.18 \%$ (45), antitusivos $1.47 \%(01)$, vitaminas $27.94 \%$ (19), ansiolíticos $1.47 \%(01)$ y ninguno $2.94 \%$ (02). 


\section{DISCUCIÓN}

La automedicación ocurrió en el $66.7 \%$ del estrato bajo mientras que sólo el $40.6 \%$ del estrato alto $(p<0.001)$ y se relacionó con: ser menor de edad, menor grado de escolaridad, ser estudiante o trabajador independiente, dolencias agudas (respiratorias y dérmicas) ${ }^{17}$. Cifras que no concuerdan con los resultados de la investigación realizada en el presente estudio donde se tienen que para los estudiantes de la carrera de enfermería que se auto medica pertenecen al nivel bajo $12,70 \%$, medio $86,50 \%$ y alto $0,80 \%$. Mientras que para los estudiantes de la carrera de obstetricia pertenecen al nivel socio económico bajo en un $7,35 \%$, medio $92,65 \%$.

Como podemos apreciar las muestras de los dos grupos socioeconómicos de nuestro estudio se comportan de manera diferente con respecto al consumo de medicamentos. Así, la proporción de menores de 15 años fue tres veces más en el estrato socioeconómico bajo que en el alto, mientras que en los consumidores geriátricos fueron cuatro veces más frecuentes en el nivel alto. Lo primero es explicable por la temprana exposición al medio externo de los niños en las zonas más deprimidas económicamente, mientras que lo segundo era de esperarse por una mayor población geriátrica, con mayores recursos, mayor expectativa de vida y mayor probabilidad de padecimientos crónicos, en el estrato alto.

Mientras que la proporción de hombres y mujeres fue la misma en el estrato socioeconómico alto por la mayor participación de la mujer en la actividad económica, en el estrato bajo encontramos que las mujeres fueron consumidores de medicamentos tres veces más que los hombres. Esto es debido a que una buena parte de ellas se dedica a labores caseras y se encarga de los cuidados de salud de la familia. ${ }^{17}$. Información que valida la investigación realizada donde las mujeres se auto medican en mayor porcentaje que los varones teniendo las siguientes cifras $85,29 \%$ del sexo femenino y $8,82 \%$ del sexo masculino datos que se proyectan a futuro donde la mujer cumple un rol importante dentro del núcleo familiar.

La automedicación, la utilización de antibióticos (ATB ) en procesos infecciosos no bacterianos y el incumplimiento terapéutico por parte del paciente son los principales problemas del empleo de ATB en atención primaria $(A P)^{18}$. La forma de auto cuidado de la salud más frecuente en España es la automedicación; siete de cada diez pacientes utilizan medidas de auto cuidado en los 15 días antes de ir a la consulta por una enfermedad de inicio, el $76 \%$ con medicamentos ${ }^{19}$. Resultados que concuerdan con la investigación realizada en la población estudiantil de la Universidad Privada de Huancayo Franklin Roosevelt con porcentajes de automedicación de $96.83 \%$ en los estudiantes de la carrera de enfermería y $94.12 \%$ en los estudiantes de la carrera de obstetricia. cifras que evidencian altos porcentajes de automedicación que pueden conllevar a problemas de resistencia bacteriana, interacciones medicamentosas y reacciones adversas.

Los ATB son el tercer grupo terapéutico (más del $30 \%$ ) con el que se auto medica la población española tras los analgésicos y antigripales ${ }^{20,21}$. Cerca del $50 \%$ de estos ATB se utiliza en infecciones de vías respiratorias superiores de etiología vírica en las que no son necesarios, lo que concuerda con trabajos sobre la utilización de ATB en la gripe y el catarro común ${ }^{21,22}$. En el $42 \%$ de los hogares españoles existe al menos un envase de antibiótico, ocupando el segundo lugar tras analgésicos/antipiréticos en el botiquín y éste es el origen frecuente del comienzo de un tratamiento conATB por automedicación ${ }^{18,21,23,24,25}$.

En un trabajo realizado en ocho centros de salud sobre automedicación encubierta con ATB, la recomendación de utilizarlos era del 49\% por sí mismo y del $24 \%$ por el farmacéutico; las indicaciones más frecuentes fueron la infección de vías respiratorias superiores $(25,5 \%)$ y faringoamigdalitis $(17,6 \%)$, dos procesos habitualmente víricos ${ }^{26}$. Los efectos negativos de la automedicación de ATB, además de la inducción de resistencia bacteriana( RBA), son su uso en situaciones en que no está indicado, enmascaramiento y retraso del diagnóstico de enfermedades y aparición de reacciones adversas e interacciones ${ }^{18,24}$. Resultados que coinciden con la investigación realizada donde se tiene que los medicamentos consumidos sin prescripción médica por los estudiantes de la carrera de enfermería son los antibióticos, analgésicos y antiinflamatorios con un $64,04 \%$ y los estudiantes de obstetricia con un $66,18 \%$ datos alarmantes que se convierten en un problema de salud pública. De acuerdo a los procesos patológicos por los que se auto medican los estudiantes de la carrera de enfermería se tiene que es por resfriado común, dolores corporales en un $47,62 \%$ y para trastornos respiratorios ,digestivos y cefaleas en un $35,83 \%$ y los estudiantes de la carrera de obstetricia para resfriado común ,dolores corporale4s en un $51,47 \%$ y prar 
trastornos respiratorios, digestivos en un $33,83 \%$

La industria farmacéutica que realiza las campañas de promoción de ATB deben tener en cuenta los patrones geográficos de RBA y el ámbito de las indicaciones de un ATB concreto, en vez de ser campañas generalizadas con el fin de influir sobre los prescriptores e incrementar el volumen de ventas ${ }^{23,27}$. La industria ha percibido el problema de las RBA más como un estímulo para la investigación de nuevas moléculas que como un problema de excesiva presión de mercado de los ATB ya comercializados, factor fundamental de sobreconsumo ${ }^{28,29,30}$. Existe una relación perversa entre la aparición de RBA y la investigación de nuevos ATB de amplio espectro para combatirlas, que podría motivar a la industria farmacéutica a realizar una presión excesiva sobre los profesionales sanitarios y la población para un consumo irracional ${ }^{30}$. Para minimizar este problema debe proporcionársele el apoyo necesario con incentivos económicos que les permita recuperar el gasto realizado en investigación y desarrollo de nuevas moléculas capaces de disminuir las RBA ${ }^{20,23,30}$. Información que valida los resultados de la investigación realizada donde se tienen que los medios de comunicación que influyeron en los alumnos de la carrera de enfermería para la automedicación fueron la televisión en un $64,28 \%$,radio $8,73 \%$,virtual $14,28 \%$,propagandas impresas $7,35 \%$ y para los estudiantes de obstetricia fueron la televisión $60,29 \%$,radio $11,76 \%$,virtual $11,76 \%$,propagandas impresas $7,35 \%$.

El consumo exagerado de ATB y la aparición de RBA están relacionados directamente con la prescripción médica inadecuada, la dispensación sin receta por los farmacéuticos y el uso indiscriminado que realizan los pacientes. Otros responsables son los laboratorios farmacéuticos por la presión que realizan sobre la prescripción y la administración sanitaria por la falta de una política de ATB en $\mathrm{AP}^{20,23,28}$. Para mejorar el uso de ATB deberíamos emprender acciones encaminadas a corregir la actuación de las personas e instituciones implicadas e instaurar políticas de uso racional de ATB en cada área sanitaria ${ }^{20,28,31}$.

Controlar las campañas de publicidad de la industria farmacéutica. El artículo 86 de la Ley del Medicamento recoge que «la información y promoción de medicamentos dirigida a los profesionales sanitarios deberá ser rigurosa, bien fundada y objetiva y no inducir a error de acuerdo con la legislación vigente, y ajustarse a la ficha técnica»" ${ }^{27}$.

\section{REFERENCIAS BIBLIOGRÁFICAS}

1. Pereta, M. Reingeniería farmacéutica.2da ed. Buenos aires: medica panamericana; 2005.

2. Angeles $\mathrm{P}$, Medina L, Molina J. Automedicación en población urbana de Cuernavaca, Morelos. Salud Pública Mex 1992; 34: 554-61.

3. Guillem P, Frances F, Gimenez F, Saiz C. Estudio sobre automedicación en población universitaria Española. Rev Clin Med Fam 2010; 3(2): 99-103.

4. Mercado G. Automedicación en el embarazo. http://www.infoadicciones.net.htm (acceso a website 10/11/2010).

5. Andamayo D, Rojas T. incidencia de automedicación en los pobladores del distrito de Pucará - Huancayo. Revista del $16^{\circ}$ Congreso Farmaceútico Argentino. Confederación Farmacéutica Argentina.

6. Riedmann P, Illesca M, Droghetti J. Automedicación en individuos de la Región de la Araucanía con problemas musculoesqueléticos. Rev Med Chile 2001; 129(6): 647-52.

7. Rondinel C. Características del consumo de medicamentos en Lima y Sauri; (Cuzco).Tesis de Bachiller de Medicina. Universidad Peruana Cayetano Heredia. Lima, 1975.

8. Núñez R. Medicina Popular y Autotratamiento en tres grupos socioeconómicos en Lima. Tesis de Bachiller de Medicina.Universidad Peruana Cayetano Heredia. Lima, 1984.

9. López R, Kroeger A. Morbilidad y Medicamentos en el Perú y Bolivia, Gráfica Bellido. Lima - Perú 1990.

Fecha de recepción: 07/04/2013

Fecha de aprobación: 08/04/2013

Correspondencia: Diana Castillo Flores

Email: dianacastilloca@hotmail.com 